\title{
Renal sympathetic denervation in mild chronic kidney disease patients with chronic heart failure without indication of cardiac resynchronization therapy: a bridge to cardiac transplantation
}

\author{
Márcio Galindo Kiuchi ${ }^{* 1}$, Shaojie Chen ${ }^{2}$ and Helmut Pürerfellner ${ }^{3}$ \\ ${ }^{1}$ Division of Cardiac Surgery and Artificial Cardiac Stimulation, Department of Medicine, Hospital e Clínica São Gonçalo, São Gonçalo, RJ, Brazil \\ ${ }^{2}$ Department of Cardiology, Shanghai First People's Hospital, Shanghai Jiao Tong University School of Medicine, Shanghai, China \\ ${ }^{3}$ Department of Cardiology, Elisabethinen University Teaching Hospital Linz, Linz, Austria
}

\begin{abstract}
Background: Heart failure (HF) is a challenging disease to control. Chronic overactivation of the sympathetic nervous system occurs early in HF and chronic kidney disease (CKD). The aim of this study was to evaluate the safety and effects of renal sympathetic denervation (RSD) in reducing lesions on the heart and kidneys in patients with CKD and chronic HF refractory pharmacological therapy and QRS complex width $<120$ ms, waiting for cardiac transplantation.

Methods and results: Eigtheen patients were included and treated with a standard irrigated cardiac ablation catheter. RSD was performed by a unique operator. All the patients included in the study had HF in functional New York Health Association (NYHA) class III, were refractory to pharmacological therapy, had QRS complex width $<120 \mathrm{~ms}$, and had mild CKD. Data were obtained at baseline, and at 6 and 12 months of follow-up. RSD was safe and feasible to perform in this population. No changes in blood pressure were observed during this period. At baseline, patients walked $146.2 \pm 18.5 \mathrm{~m}$ during a 6 minutes walking test, increasing to $201.6 \pm 21.8 \mathrm{~m}$ at 12 months post RSD ( $<<0.0001)$. All echocardiographic parameters evaluated improved at 6 and 12 months ( $<<0.05)$ after RSD. Estimated glomerular filtration rate improved from $73.6 \pm 8.7 \mathrm{~mL} / \mathrm{min} / 1.73 \mathrm{~m} 2$ at baseline to $88.0 \pm 10.1 \mathrm{~mL} / \mathrm{min} / 1.73 \mathrm{~m} 2$ at $12 \mathrm{months}$ post procedure (p<0.0001). At 12 months after RSD, $11 \%$ of patients were in functional NYHA class I, 72\% were in functional class II, and 17\% remained in functional NYHA class III.
\end{abstract}

Conclusions: RSD seemed to be safe, feasible, and effective, resulting in an improvement in echocardiographic parameters, 6 minutes walking test distance, renal function, and functional NYHA class in mild CKD patients with HF refractory to pharmacological therapy and QRS $<120$ ms.

\section{Introduction}

Patients with heart failure (HF) are often refractory to pharmacologic treatment, including a combination of suppressive agents of the renin-angiotensin-aldosterone (RAA) system or in several times they do not have an indication of cardiac resynchronization therapy (CRT), remaining symptomatic and in an advanced functional New York Health Association (NYHA) class. They thus contribute to the highest number of hospitalizations and an increased mortality rate. Adequate control of $\mathrm{HF}$ and its progression is sometimes a difficult goal to achieve in this patient population, and in most cases, is only resolved after heart transplantation, which in turn is not easily accessible. However, many of these patients do not have enough time to be submitted to the cardiac transplantation and die before. Recently, Berukstis and colleagues [1] reported that renal sympathetic denervation (RSD) offers an innovative and safe catheter-based approach for selective reduction of the renal sympathetic drive. They demonstrated that selective denervation of sympathetic nerves in the renal arteries significantly reduced sympathetic cardiac overdrive, as assessed by 123I metaiodobenzylguanidine (MIBG) scintigraphy, thus positively affecting HF progression.

Chronic overactivation of the sympathetic nervous system is a major component of HF [2-4] and chronic kidney disease (CKD), occurring in the early clinical course of the disease [5], and involves both afferent and efferent pathways between the brain and numerous organs [6]. RSD has been shown to be effective in refractory hypertensive CKD patients [7]. Although in principle this intervention could help ameliorate the neurohormonal imbalance in chronic HF $[8,9]$, in practice, there are concerns because patients with HF typically have normal or low blood pressure (BP), and therefore, may present with worse symptoms after RSD because their BP can subsequently fall. The aim of this study was to evaluate the safety and effects of RSD in reducing damage to the heart and kidneys in CKD patients with HF without indication of CRT.

\section{Methods}

This prospective, longitudinal study was conducted in 18 patients

Correspondence to: Márcio Galindo Kiuchi, Division of Cardiac Surgery and Artificial Cardiac Stimulation, Department of Medicine, Hospital e Clínica São Gonçalo, São Gonçalo, RJ, Brazil

Key words: chronic kidney disease, refractory heart failure, renal sympathetic denervation, echocardiographic parameters, cardiac transplantation

Received: November 06, 2016; Accepted: November 26, 2016; Published: November 28, 2016 
Kiuchi MG (2016) Renal sympathetic denervation in mild chronic kidney disease patients with chronic heart failure without indication of cardiac resynchronization therapy: a bridge to cardiac transplantation

with refractory HF who underwent percutaneous RSD. The study was approved by the Hospital e Clínica São Gonçalo Ethics Committee in partnership with Elisabethinen Krankenhaus, Linz, Austria, and conducted in accordance with the principles of the Declaration of Helsinki. All patients signed written informed consent prior to study inclusion. We evaluated the safety and effectiveness of RSD for improvement of clinical parameters and in reducing damage to the heart, through echocardiographic parameters, and kidneys, by assessing estimated glomerular filtration rate (eGFR) and albumin:creatinine ratio (ACR), in patients with $\mathrm{HF}$ and without indication of CRT.

\section{Study subjects}

This study was conducted at the Hospital e Clínica São Gonçalo, Rio de Janeiro, Brazil, where patients were recruited from June 2013 through to January 2015 from the Artificial Cardiac Pacing Department. Patients meeting all the following criteria were consecutively enrolled: (i) office systolic $\mathrm{BP} \geq 110 \mathrm{mmHg}$; (ii) aged between 18 and 80 years; (iii) chronic HF due to systolic dysfunction and functional NYHA class III; (iv) left ventricular ejection fraction $\leq 35 \%$ measured by Simpson's method in the echocardiogram; (v) present QRS complex width <120 ms; (vi) optimized drug therapy for HF, including the maximum tolerated dose of recommended agents, e.g., beta-blockers, angiotensin-converting enzyme (ACE) inhibitors or angiotensin II receptor blockers (ARB), and spironolactone [10] (vii) sinus rhythm; (viii) eGFR determined using the Chronic Kidney Disease Epidemiology Collaboration (CKDEPI) equation, eGFR [11] $>60 \mathrm{~mL} / \mathrm{min} / 1.73 \mathrm{~m}^{2}$ these patients were required to have microalbuminuria); and (ix) able to read, understand and sign the informed consent form.

Patients with any of the following criteria were excluded: (i) pregnancy; (ii) acute HF; (iii) acute coronary syndrome; (iv) valvular disease with significant hemodynamic repercussions; (v) myocardial infarction, unstable angina, stroke or transient ischemic attack within the previous 6 months; (vi) renovascular abnormalities (including severe renal artery stenosis, and renal angioplasty with or without stenting); (vii) psychiatric disease; (viii) allergy to ionic contrast; (ix) unable to be followed clinically after the procedure; (x) known to have drug or alcohol addiction, which can affect the ability to understand or follow medical instructions; (xi) a serious disease, which in the opinion of the investigator, may adversely affect the safety and/or efficacy of the participant or the study (e.g., patients with clinically significant peripheral vascular disease, abdominal aortic aneurysm, diseases that may cause bleeding with thrombocytopenia, hemophilia, or significant anemia).

\section{Transthoracic echocardiography}

Transthoracic echocardiography was performed at baseline and at 6 months after RSD using a GE ultrasound system (Vivid I, General Electric, Frankfurt, Germany) equipped with a multi-frequency transducer and tissue Doppler imaging software according to the Guidelines of the American Society of Echocardiography [12]. Data were analyzed and interpreted by one experienced echocardiographer blinded to treatment status, HF stage, and the sequence of the images. Left ventricular (LV) mass was calculated from LV linear dimensions using the Devereux formula $[12,13]$. LV mass was indexed to body surface area [12,14], as indicated.

\section{Twenty-four hour ABPM}

The ABPM was performed for 24 hours with a clinically validated device (CardioMapa; Cardios, São Paulo, Brazil) at baseline. The device was designed to measure every 15 minutes during daytime (from 6 to 22 hours) and every 30 minutes during the night (from 22 to 6 hours). The patients were instructed to continue their regular activities during recording and go to the bed not later than 23:00 hours. The wakefulness ranged from 8 to 22 hours and the sleep period from midnight till 6:00 am [15]. All subjects were trained to record in a diary the hours during which they took their meals, as well as periods of sleep and wakefulness, ingestion of drugs, in addition to symptoms and events that could influence blood pressure during this period. The measurements were transferred to a computer for analysis. The monitoring was repeated as necessary until $\geq 70 \%$ of day and night values measured were satisfactory [16].

\section{Study procedures and assessment}

In total, 18 patients (15 men and 3 women) with HF in functional NYHA class III without criteria to CRT implantation were treated in this study. All patients underwent a complete medical history and physical examination, and their HF medication was reviewed. BP was measured in the standing, sitting, and supine positions on at least two subsequent visits in both arms. Blood samples were collected to determine a complete blood count, biochemistry (including serum creatinine to estimate GFR), and brain natriuretic peptide (BNP). Urine samples were obtained to determine albuminuria, protein, and creatinine levels. Twenty-four hour ambulatory BP monitoring (ABPM), echocardiogram, 6 minutes walking test, and Echo Doppler evaluation of the anatomy of the renal arteries of patients were also assessed.

To evaluate the true effects of RSD on HF and additional measures, baseline medication was unchanged for at least 3 months before RSD and treatment were maintained at follow-up. Patients were instructed not to change their medication and dosages after the procedure unless clinically indicated. For all patients, drug records and adherence were comprehensively reviewed and documented at each visit.

\section{Renal sympathetic denervation}

The RSD procedure has been described in detail previously [17]. The patients remained hospitalized in the ward for $24 \mathrm{~h}$ after the procedure. Follow-up was performed weekly for the first month and monthly from the second to the 12th month. At each visit to the office, functional NYHA class was evaluated, the medication was revised, and BP was measured after standing for $10 \mathrm{~min}$ in both upper limbs, and in the sitting and supine positions. There was a pause of $5 \mathrm{~min}$ between every change in patient position (standing, sitting, and supine). The mean of four BP measurements was considered for the study. Samples were collected for blood and urine tests to monitor variables and BNP. In addition, 24-hour ABPM, 6 minutes walking test, and echocardiogram were performed at 6 and 12 months after RSD. Echo Doppler was also performed to evaluate the anatomy of the renal arteries of patients at 6 months after RSD. The following variables were monitored during the follow-up period: echocardiographic parameters, systolic and diastolic $\mathrm{BP}$, number and dose of medication, eGFR, albuminuria, BNP, and 6 minutes walking test.

\section{Statistical analysis}

Results are expressed as the mean and standard deviation (mean \pm SD), in the case of normal distribution, or as the median with inter-quartile range. Statistical tests were all two sided. Comparisons between two-paired values were performed by the paired t-test in the case of Gaussian distribution or, alternatively, by the Wilcoxon test. 
Kiuchi MG (2016) Renal sympathetic denervation in mild chronic kidney disease patients with chronic heart failure without indication of cardiac resynchronization therapy: a bridge to cardiac transplantation

Comparisons between more than two-paired values were performed by ANOVA for repeated measures or with Kruskal-Wallis ANOVA as appropriate, complemented by a post hoc test. Frequencies were compared with Fisher's exact test. P-values $<0.05$ were considered statistically significant. Correlations between two variables were performed by the Pearson method in the case of Gaussian distribution or, alternatively, with the Spearman correlation test. All statistical analyses were performed using Graphpad Prism version 7.0 (Graphpad software, La Jolla, CA, USA).

\section{Results}

\section{Baseline patient characteristics}

General baseline characteristics of the 18 HF patients are listed in Table 1; all patients were in functional NYHA class III. Mean office systolic/diastolic BP was $130 \pm 8 / 82 \pm 5 \mathrm{mmHg}$. Mean LV ejection fraction (LVEF) was $26.2 \pm 5.6 \%$.

\section{Safety evaluation of renal sympathetic denervation in heart failure}

No patient was re-admitted for HF symptoms or procedural complications during follow-up. No hypotensive (systolic BP $<90$ $\mathrm{mmHg}$ ) [10] or syncopal episodes were reported. Real-time renal artery imaging was performed to assess potential structural changes related to the procedure. Some small focal irregularities of the renal arteries that were present during the procedure (possibly due to minor spasm or edema) were no longer seen postoperatively. At 6 months post-procedure, all patients underwent a Doppler scan of renal arteries, and there was no evidence of stenosis or flow limitation.

Post-procedure effects on blood pressure, QRS complex width, brain natriuretic peptide, renal function, and heart failure medications

At 6 and 12 months after RSD, there was a nonsignificant change in office BP and 24-hour ABPM, as shown in Table 2. Effects of RSD on creatinine values, eGFR, albumin:creatinine ratio, BNP and QRS complex width in all patients are also shown in Table 2. Changes in the use of each class of HF medication before and after RSD are shown in Table 3.

\section{Changes in 6 minutes walking test parameters}

During the 6 minutes walking test, patients walked $146.2 \pm 18.5$ meters at baseline; however, at 6 and 12 months post RSD, the distance walked during 6 minutes was $180.3 \pm 22.7$ meters $(\mathrm{P}<0.0001)$ and $201.6 \pm 21.8$ meters $(\mathrm{P}<0.0001)$, respectively, as shown in Figure 1. Comparing the distances covered between 6 and 12 months, there was a significant difference $(\mathrm{P}=0.0105)$.

\section{Changes in echocardiographic parameters}

Table 4 shows the effects of RSD at baseline, 6, and 12 months of follow-up on echocardiographic parameters: LVEF, end diastolic left ventricular diameter (EDLVD), end diastolic left ventricular volume (EDLVV), end systolic left ventricular diameter (ESLVD), end systolic left ventricular volume (ESLVV), left ventricular mass, end diastolic posterior wall thickness (EDPWT), and end diastolic inter ventricular septum thickness (EDIVST). Compared with baseline, all parameters were statistically significantly changed at both 6 and 12 months after RSD.

\section{Changes in functional class of heart failure}

At baseline, all the HF patients were in functional NYHA class III; however, 12 months after RSD 11\% were in functional class I, $72 \%$ were in functional class II, and $17 \%$ remained in functional class III, $\mathrm{P}<0.0001$ (Figure 2).

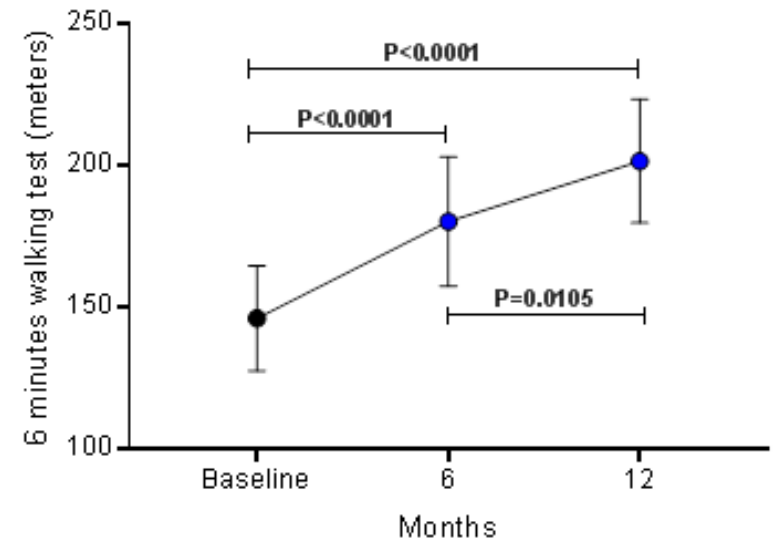

Figure 1. Increase in 6 minutes walking test distance over 12 months after renal sympathetic denervation. Values are presented as mean $\pm \mathrm{SD}$.

Table 2. Parameters at baseline $v s .6^{\text {th }}$ and $12^{\text {th }}$ month after renal sympathetic denervation.

\begin{tabular}{|l|c|}
\hline $\mathrm{N}$ & 18 \\
\hline Age, years & $64.6 \pm 12.3^{\mathrm{a}}$ \\
\hline Body mass index, $\mathrm{kg} / \mathrm{m}^{2}$ & $28.8 \pm 3.1^{\mathrm{a}}$ \\
\hline Male sex, \% & $15(83 \%)$ \\
\hline White ethnicity, \% & $18(100 \%)$ \\
\hline Cardiomyopathy of non-ischemic etiology, $\%$ & $13(72 \%)$ \\
\hline Type 2 Diabetes Mellitus, \% & $11(61 \%)$ \\
\hline eGFR, mL/min/1.73m ${ }^{2}$ (CKD-EPI) & $73.6 \pm 8.7^{\mathrm{a}}$ \\
\hline Functional class (NYHA III) & $18(100 \%)$ \\
\hline LVEF (Simpson), $\%$ & $26.2 \pm 5.6^{\mathrm{a}}$ \\
\hline Office blood pressure, mmHg & $130 \pm 8 / 82 \pm 5^{\mathrm{a}}$ \\
\hline 24-hour ABPM, mmHg & $121 \pm 7 / 74 \pm 5^{\mathrm{a}}$ \\
\hline
\end{tabular}

Mean \pm SD; ABPM, ambulatory blood pressure measurements; eGFR, estimated glomerular filtration rate; LVEF, left ventricular ejection fraction; $\mathrm{N}$, number of patients; NYHA, New York Heart Association.

\begin{tabular}{|c|c|c|c|c|c|}
\hline Variable & Baseline $(n=18)$ & $6^{\text {th }}$ month $(\mathrm{n}=18)$ & $\begin{array}{c}\text { P-value } \\
6^{\text {th }} \text { month } v s . \text { baseline }\end{array}$ & $12^{\text {th }}$ month $(\mathrm{n}=18)$ & $\begin{array}{c}\text { P-value } \\
12^{\text {th }} \text { month } v \text { s. baseline }\end{array}$ \\
\hline Office BP, mmHg & $130 \pm 8 / 82 \pm 5$ & $127 \pm 4 / 82 \pm 6$ & $0.2896 />0.9999$ & $126 \pm 5 / 85 \pm 2$ & $0.1157 / 0.1397$ \\
\hline 24-hour ABPM, mmHg & $121 \pm 7 / 74 \pm 5$ & $122 \pm 3 / 72 \pm 8$ & $0.8364 / 0.5714$ & $120 \pm 5 / 76 \pm 4$ & $0.8364 / 0.5714$ \\
\hline QRS complex, ms & $111.8 \pm 7.0$ & $112.4 \pm 5.7$ & 0.9594 & $110.9 \pm 6.9$ & 0.9110 \\
\hline BNP, pg/mL & $264.1 \pm 50.8$ & $216.8 \pm 47.3$ & 0.0054 & $187.4 \pm 28.8$ & $<0.0001$ \\
\hline Creatinine, $\mathrm{mg} / \mathrm{dL}$ & $1.10 \pm 0.21$ & $0.93 \pm 0.09$ & 0.0042 & $0.90 \pm 0.13$ & 0.0007 \\
\hline $\mathrm{eGFR}, \mathrm{mL} / \mathrm{min} / 1.73 \mathrm{~m}^{2}$ (CKD-EPI) & $73.6 \pm 8.7$ & $85.1 \pm 7.5$ & 0.0008 & $88.0 \pm 10.1$ & $<0.0001$ \\
\hline $\mathrm{ACR}, \mathrm{mg} / \mathrm{g}$ & $68.1 \pm 20.6$ & $29.6 \pm 13.8$ & $<0.0001$ & $19.4 \pm 9.6$ & $<0.0001$ \\
\hline
\end{tabular}

Values are presented as mean $\pm \mathrm{SD}$; ABPM, ambulatory blood pressure measurements; ACR, albumin:creatinine ratio; BNP, brain natriuretic peptide; BP, blood pressure; eGFR, estimated glomerular filtration rate. 
Kiuchi MG (2016) Renal sympathetic denervation in mild chronic kidney disease patients with chronic heart failure without indication of cardiac resynchronization therapy: a bridge to cardiac transplantation

\section{Discussion}

Our study results show a reduction from baseline in creatinine levels $(0.20 \mathrm{mg} / \mathrm{dL})$, a consequent increase in eGFR $(14.5 \mathrm{~mL} /$ $\left.\mathrm{min} / 1.73 \mathrm{~m}^{2}\right)$, and a reduction in ACR $(48.7 \mathrm{mg} / \mathrm{g})$ at $12 \mathrm{months}$ after the RSD procedure. These data are in concordance with our findings obtained in a long-term study in hypertensive patients with mildto-moderate CKD [18]. These results suggest that in mild CKD, an improvement in echocardiographic cardiac parameters occurs, which benefits these patients and reduces the severity of HF. We attribute this improvement in HF as most likely due to reversal of sympathetic hyperactivity resulting in reverse cardiac remodeling, as reported by Berukstis and colleaguesn [1] RSD offers an innovative and safe catheter-based approach for selective reduction of the renal sympathetic drive, showing that selective denervation of sympathetic nerves in the renal arteries significantly reduced cardiac sympathetic overdrive, as assessed by 123 I metaiodobenzylguanidine (MIBG) scintigraphy, thus positively affecting HF progression.

HF is a very common condition in our country, Brazil. Not always CRT is indicated as therapy for patients with advanced refractory HF. When HF is completely refractory to therapy, cardiac assist devices and heart transplantation are needed [10]. Activation of renal nerves in chronic HF can cause a reflex increase in sympathetic tone, leading to a sympathetic hyperactivity state, which contributes to high peripheral

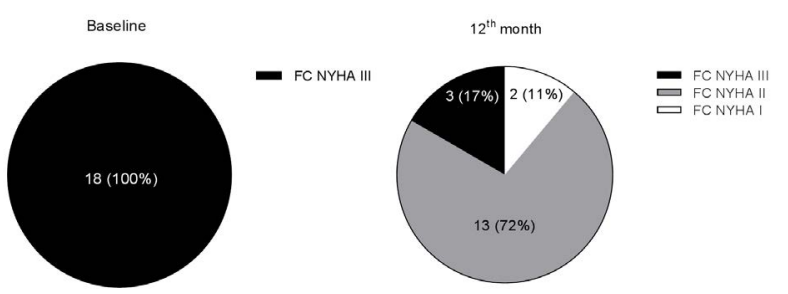

Figure 2. Functional New York Health Association (NYHA) class (FC) of heart failure distribution at baseline and 12 months after renal sympathetic denervation.

Table 3. Medication use by class before, 6 and 12 months after denervation sympathetic denervation.

\begin{tabular}{|l|c|c|c|}
\hline Patient & Baseline (n=18) & $\mathbf{6}^{\text {th }}$ month $(\mathbf{n}=\mathbf{1 8})$ & $\mathbf{1 2}^{\text {th }}$ month (n=18) \\
\hline ACE-inhibitors & $7(39 \%)$ & $7(39 \%)$ & $7(39 \%)$ \\
\hline $\begin{array}{l}\text { Angiotensin-receptor } \\
\text { blocker }\end{array}$ & $11(61 \%)$ & $11(61 \%)$ & $11(61 \%)$ \\
\hline$\beta$-blocker & $18(100 \%)$ & $18(100 \%)$ & $18(100 \%)$ \\
\hline Loop diuretic & $18(100 \%)$ & $18(100 \%)$ & $18(100 \%)$ \\
\hline $\begin{array}{l}\text { Aldosterone } \\
\text { antagonist }\end{array}$ & $18(100 \%)$ & $18(100 \%)$ & $18(100 \%)$ \\
\hline Digoxin & $18(100 \%)$ & $18(100 \%)$ & $18(100 \%)$ \\
\hline
\end{tabular}

ACE, angiotensin-converting enzyme; Values are expressed as number (percentage). vascular resistance, vascular remodeling, as well as remodeling and LV dysfunction [19-22]. Sympathetic hyperactivity is well known to increase cardiovascular risk in CKD patients, and the sympathetic hyperactivity in CKD patients appears to be expressed at the initial clinical stage of the disease, showing a direct relationship with the severity of renal impairment [5,23-25]. Interruption of sympathetic hyperactivity and feedback from the RAA system can at least partly be beneficial for this population. Based on these pathophysiological mechanisms, RSD in patients with CKD and chronic HF refractory to optimized treatment may be effective in reducing damage to the heart and kidneys.

In a small study, 'the first performed in humans', in seven normotensive patients with severe chronic HF, 6 months after receiving $\mathrm{RSD}$, the distance walked by patients in their 6-minute walk test increased significantly, and their evaluation of self-wellness was also improved [26]. Recently, Dai and colleagues also reported improvements in symptoms of severe chronic HF after RSD in 10 patients, and no complications were recorded in this study [27]. These data corroborate our findings 12 months after RSD. Compared with baseline, BNP levels were reduced $(76.7 \mathrm{pg} / \mathrm{mL}), 6$ minutes walking test distance was increased $(55.4 \mathrm{~m})$, and the HF functional NYHA class was improved in $83 \%$ of the patients. Moreover, no complications occurred, and BP, both office, and 24-hour ABPM, remained stable. This is similar to the results described by Davies and colleagues, even in normotensive patients [26]. Although Dai .and colleagues [27] described an improvement in LVEF, we did not expect to see the same because of the severity of HF of our patients, who are refractory to pharmacological treatment and are classified out of therapeutic possibility, just waiting for cardiac transplantation. However, we observed improvements in all echocardiographic parameters evaluated 12-months post RSD, allowing us to gain more time until the heart transplantation. The results reported by Berukstis and colleagues [1] reported that RSD offers an innovative and safe catheter-based approach for selective reduction of the renal sympathetic drive, which may explain, in part, our results. Previously, we described improvements in these parameters in 45 patients at 6 months post RSD, but these patients had resistant hypertension, LV hypertrophy, and CKD [28].

\section{Study limitations}

This study was a safety evaluation and was therefore neither blinded nor powered to assess clinical efficacy. Whilst there was a self-reported improvement in symptoms (functional NYHA class), echocardiographic parameters, BNP levels, renal function, and an observed increase in 6 minutes walking distance, these findings should

Table 4. Echocardiographic parameters at baseline $v s .6^{\text {th }}$ and $12^{\text {th }}$ month after renal sympathetic denervation.

\begin{tabular}{|c|c|c|c|c|c|}
\hline Variable & Baseline (n=18) & $6^{\text {th }}$ month $(n=18)$ & $\begin{array}{c}\text { P-value } \\
6^{\text {th }} \text { month } v \text { s. baseline }\end{array}$ & $12^{\text {th }}$ month $(\mathrm{n}=18)$ & $\begin{array}{c}\text { P-value } \\
12^{\text {th }} \text { month } v \text { s. baseline }\end{array}$ \\
\hline LVEF (Simpson), \% & $26.2 \pm 5.6$ & $30.4 \pm 3.3$ & 0.0122 & $32.3 \pm 3.4$ & 0.0002 \\
\hline EDLVD, $\mathrm{mm}$ & $68.5 \pm 6.6$ & $64.3 \pm 3.9$ & 0.0386 & $63.1 \pm 4.0$ & 0.0058 \\
\hline EDLVV, mL & $189.2 \pm 12.5$ & $168.0 \pm 12.3$ & 0.0003 & $158.5 \pm 19.8$ & $<0.0001$ \\
\hline ESLVD, mm & $56.8 \pm 6.4$ & $52.6 \pm 2.9$ & 0.0174 & $51.3 \pm 3.1$ & 0.0014 \\
\hline ESLVV, mL & $158.0 \pm 13.7$ & $147.5 \pm 10.9$ & 0.0238 & $141.2 \pm 9.8$ & 0.0002 \\
\hline LV mass, $\mathrm{g} / \mathrm{m}^{2}$ & $232.8 \pm 30.0$ & $203.1 \pm 25.4$ & 0.0118 & $194.6 \pm 33.5$ & 0.0010 \\
\hline EDPWT, mm & $12.0 \pm 0.9$ & $10.9 \pm 1.0$ & 0.0009 & $10.5 \pm 0.6$ & $<0.0001$ \\
\hline EDIVST, mm & $11.6 \pm 1.0$ & $10.5 \pm 0.9$ & 0.0006 & $10.2 \pm 0.5$ & $<0.0001$ \\
\hline
\end{tabular}

Values are presented as mean \pm SD. LVEF, left ventricular ejection fraction; EDLVD, end diastolic left ventricular diameter; EDLVV, end diastolic left ventricular volume; ESLVD, end systolic left ventricular diameter; ESLVV, end systolic left ventricular volume; LV, left ventricular; EDPWT, end diastolic posterior wall thickness; EDIVST, end diastolic inter ventricular septum thickness. 
Kiuchi MG (2016) Renal sympathetic denervation in mild chronic kidney disease patients with chronic heart failure without indication of cardiac resynchronization therapy: a bridge to cardiac transplantation

be interpreted with caution given the un-blinded non-randomized nature of the study. A randomized trial with appropriate blinding of treatment is required to address the potential benefits of RSD in chronic HF refractory pharmacological treatment and QRS width $<120 \mathrm{~ms}$.

The use of echo Doppler to assess damage in the renal arteries is in some way a limitation. However, early complications caused by the RF applications were excluded by angiography performed at the end of the procedure. Any other method, such as computed tomography angiography or a new angiography of the renal arteries, could expose patients to additional undesirable toxic insults. Angiography using $\mathrm{CO}_{2}$ is not available at our center.

The evaluation of heart rate was compromised in this study, primarily because of the use of maximum dose beta-blockers and digoxin. In addition, more precise methods for the assessment of GFR, such as cystatin $\mathrm{C}$ or iothalamate, should be used in future studies to confirm our findings regarding the effects of RSD upon eGFR, especially considering that only one measurement of serum creatinine was performed at each time point in our study.

\section{Conclusion}

Many of the factors reported above can lead to cardiac transplantation and sudden cardiac death in this population, particularly if these patients reach the end stage of renal disease or remain in a stage of HF refractory to optimized medication, waiting for cardiac transplantation. However, these factors appear to be modified by RSD, as reported in the studies discussed above, which leads us to consider this new tool to modify such risk factors, which until now have not been modifiable. Although encouraging, our data are preliminary and need to be validated in a large population and in long-term studies.

\section{Funding}

This study was funded by Pacemed (USD\$400,000).

\section{Conflict of interest}

None declared.

\section{Acknowledgements}

The authors would like to thank all the participants in this study, and also Pacemed for stimulating the development of this research and for technical support.

\section{References}

1. Berukstis A, Vajauskas D, Gargalskaite U, Misonis N, Burneikaite G, et al. (2016) A. Impact of renal sympathetic denervation on cardiac sympathetic nerve activity evaluated by cardiac MIBG imaging. EuroIntervention 11: 1070-1076.

2. Petersson M, Friberg P, Eisenhofer G, Lambert G, Rundqvist B (2005) Long-term outcome in relation to renal sympathetic activity in patients with chronic heart failure. Eur Heart J 26: 906-913. [Crossref]

3. Hasking GJ, Esler MD, Jennings GL, Burton D (1986) Norepinephrine spillover to plasma in patients with congestive heart failure: evidence of increased overall and cardiorenal sympathetic nervous activity. Circulation 986: 615-621.

4. Schultz HD, Li YL, Ding Y (2007) Arterial chemoreceptors and sympathetic nerve activity: implications for hypertension and heart failure. Hypertension 50: 6-13. [Crossref]

5. Tinucci T, Abrahão SB, Santello JL, Mion D Jr (2001) Mild chronic renal insufficiency induces sympathetic overactivity. J Hum Hypertens 15: 401-406. [Crossref]

6. Sobotka PA, Krum H, Böhm M, Francis DP, Schlaich MP (2012) The role of renal denervation in the treatment of heart failure. Curr Cardiol Rep 14: 285-292. [Crossref]

7. Kiuchi MG, Maia GL, de Queiroz Carreira MA, Kiuchi T, et al. (2013) Effects of renal denervation with a standard irrigated cardiac ablation catheter on blood pressure and renal function in patients with chronic kidney disease and resistant hypertension. Eur Heart J 34: 2114-2121.

8. Zucker IH (2006) Novel mechanisms of sympathetic regulation in chronic heart failure Hypertension 48: 1005-1011. [Crossref]

9. Nozawa T, Igawa A, Fujii N, Kato B-I, Yoshida N, et al. (2002) Effects of long-term renal sympathetic denervation on heart failure after myocardial infarction in rats. Heart Vessels 16: 51-56.

10. McMurray JJ, Adamopoulos S, Anker SD, Auricchio A, Böhm M, et al. (2012) ESC Committee for Practice Guidelines. ESC Guidelines for the diagnosis and treatment of acute and chronic heart failure 2012: The Task Force for the Diagnosis and Treatment of Acute and Chronic Heart Failure 2012 of the European Society of Cardiology. Developed in collaboration with the Heart Failure Association (HFA) of the ESC. Eur Heart J 33: 1787-1847.

11. Levey AS, Stevens LA, Schmid CH, Zhang YL, Castro III AF, et al. (2009) CKD-EP (Chronic Kidney Disease Epidemiology Collaboration). A new equation to estimate glomerular filtration rate, Ann Intern Med 150: 604-612.

12. Lang RM, Bierig M, Devereux RB, Flachskampf FA, Foster E, Pellikka PA, et al. (2005) Recommendations for chamber quantification: a report from the American Society of Echocardiography's Guidelines and Standards Committee and the Chamber Quantification Writing Group, J Am Soc Echocardiogr 18: 1440-1463.

13. Devereux RB, Alonso DR, Lutas EM, Gottlieb GJ, Campo E, et al. (1986) Echocardiographic assessment of left ventricular hypertrophy: comparison to necropsy findings. Am J Cardiol 57: 450-458. [Crossref]

14. Mosteller RD (1987) Simplified calculation of body-surface area. N Engl J Med 317: 1098. [Crossref]

15. Mancia G, De Backer G, Dominiczak A, Cifkova R, Fagard R, Germano G, et al. (2007) Management of Arterial Hypertension of the European Society of Hypertension; European Society of Cardiology. Management of Arterial Hypertension of the European Society of Hypertension European Society of Cardiology: 2007 Guidelines for the Management of Arterial Hypertension: The Task Force for the Management of Arterial Hypertension of the European Society of Hypertension (ESH) and of the European Society of Cardiology (ESC). J Hypertens 25: 1105-1187.

16. Stergiou GS, Kollias A, Destounis A, Tzamouranis D (2012) Automated blood pressure measurement in atrial fibrillation: a systematic review and meta-analysis. $J$ Hypertens 30: 2074-2082.

17. Kiuchi MG, E Silva GR, Paz LM, Chen S, Souto GL (2016) Proof of concept study: renal sympathetic denervation for treatment of polymorphic premature ventricular complexes. J Interv Card Electrophysiol

18. Kiuchi MG, Graciano ML, Carreira MA, Kiuchi T, Chen S, et al. (2015) Long-Term Effects of Renal Sympathetic Denervation on Hypertensive Patients With Mild to Moderate Chronic Kidney Disease. J Clin Hypertens (Greenwich).

19. Cohn JN, Johnson G, Ziesche S, Cobb F, Francis G, et al. (1991) A comparison of enalapril with hydralazine-isosorbide dinitrate in the treatment of chronic congestive heart failure. $N$ Engl J Med 325: 303-310. [Crossref]

20. [No authors listed] (1987) Effects of enalapril on mortality in severe congestive hear failure. Results of the Cooperative North Scandinavian Enalapril Survival Study (CONSENSUS). The CONSENSUS Trial Study Group. N Engl J Med 316: 1429-1435. [Crossref]

21. [No authors listed] (1991) Effect of enalapril on survival in patients with reduced left ventricular ejection fractions and congestive heart failure. The SOLVD Investigators. $N$ Engl J Med 325: 293-302. [Crossref]

22. The SOLVD Investigators. Effect of enalapril on mortality and the development of heart failure in asymptomatic patients with reduced left ventricular ejection fractions. N Engl J Med 327: 685-691.

23. Schlaich MP, Socratous F, Hennebry S, Eikelis N, Lambert EA, et al. (2009) Sympathetic activation in chronic renal failure. J Am Soc Nephrol 20: 933-939. [Crossref]

24. Neumann J, Ligtenberg G, Klein II, Koomans HA, Blankestijn PJ (2004) Sympathetic hyperactivity in chronic kidney disease: pathogenesis, clinical relevance, and treatment. Kidney Int 65: 1568-1576.

25. Grassi G, Bertoli S, Seravalle G (2012) Sympathetic nervous system: role in hypertension and in chronic kidney disease. Curr Opin Nephrol Hypertens 21: 46-51. [Crossref]

26. Davies JE, Manisty CH, Petraco R, Barron AJ, Unsworth B, Mayet J, et al. (2013) Firstin-man safety evaluation of renal denervation for chronic systolic heart failure: primary 
Kiuchi MG (2016) Renal sympathetic denervation in mild chronic kidney disease patients with chronic heart failure without indication of cardiac resynchronization therapy: a bridge to cardiac transplantation

outcome from REACH-Pilot study. Int J Cardiol 162:189-192.

27. Dai Q, Lu J, Wang B, Ma G (2015) Effect of percutaneous renal sympathetic nerve radiofrequency ablation in patients with severe heart failure. Int J Clin Exp Med 8: 9779-9785.
28. Kiuchi MG, Mion D Jr, Graciano ML, de Queiroz Carreira MA, Kiuchi T, et al. (2016) Proof of concept study: Improvement of echocardiographic parameters after renal sympathetic denervation in CKD refractory hypertensive patients. Int J Cardiol 207: 6-12.

Copyright: (C2016 Galindo Kiuchi M. This is an open-access article distributed under the terms of the Creative Commons Attribution License, which permits unrestricted use, distribution, and reproduction in any medium, provided the original author and source are credited. 